\title{
Should Homocysteine be a Therapeutic Target for Neurological Disorders?
}

\section{Jin Jun Luo ${ }^{1,2 *}$ and Nae J Dun ${ }^{2}$}

${ }^{1}$ Department of Neurology, Temple University School of Medicine, Philadelphia, PA 19140, USA

${ }^{2}$ Department of Pharmacology, Temple University School of Medicine, Philadelphia, PA 19140, USA

Recent clinical and laboratory findings have attracted much interest in homocysteine (Hcy) because the latter is relevant to numerous medical conditions. Elevated plasma level of Hcy (eHcy) is a recognized independent risk factor for cardiovascular disorders [1,2], causing arthrosclerosis and myocardial infarction. Additionally, eHcy has been observed in a number of neurological disorders including stroke [3], dementia, Alzheimer's disease (AD) [4], Parkinson's disease (PD) [5], and amyotrophic lateral sclerosis (ALS) [6].

Hcy is an intermediate metabolite of the essential amino acid methionine involving DNA metabolism via mythylation. Hcy can be converted into either methionine or cystathione by the enzymes methionine synthase, which requires B12 as a cofactor to remethylate Hcy to methionine, or cystathione $\beta$-synthase, which controls transsulfuration of Hcy to cystathione and requires B6 as a cofactor; and methyltetrahydrofolate reductase (MTHFR), which requires folate for reaction. In physiologic conditions, Hcy is converted to methionine which is activated by ATP to form S-adenosylmethionine (SAM) and serves as a universal methyl donor. The transfer of SAM's methyl group to an acceptor molecule generates $\mathrm{S}$-adenosylhomocysteine (SAH) which is then hydrolyzed and regenerates homocysteine [7]. This hydrolysis is a reversible reaction that favors the synthesis of SAH which is also a potent inhibitor of methylase enzymes. Thus, an elevated intracellular SAH or a low SAM/SAH ratio may predict methylation deficits [7], which are critical for neurological function. The plasma level of Hcy is determined primarily by adequate dietary intake and vitamin status. eHcy can be caused by either a deficiency of B12 or folic acid alone, or in combination, or genetic factors, such as C667T MTHFR polymorphism.

eHcy likely exerts its adverse effects via direct and indirect intracellular actions. For example, eHcy stimulates free radical production, provokes oxidative stress response, increases cytosolic calcium level, interferes with mitochondrial function, depletes ATP reserve, impairs transmethylation of DNA causing DNA breakage, and results in hypersensitivity to excitotoxicity and apoptosis [8-10]. Of note, depletion of cellular ATP is a pivotal factor in neurodegenerative disorders such as AD, PD, ALS, and Huntingdon's disease [11,12]. eHcy may potentiate synaptic glutamate receptor activity either directly [13] or indirectly via its metabolite L-homocysteic acid [14], thereby altering synaptic functions. These actions can be diminished by metabotropic glutamate receptor antagonists $[10,15]$. Further, eHcy may compromise anti-oxidative capacity by decreasing glutathione peroxidase activity [16] and tissue levels of vitamins A, C and E [17]. These adverse effects of eHcy on anti-oxidative activity occur at multiple levels and can be modified by administration of N-acetyl-Lcysteine, vitamin $\mathrm{C}$ or vitamin $\mathrm{E}$ [18]. Interestingly, supplementation of folate is not as effective as $\mathrm{N}$-acetyl-L-cysteine, vitamin $\mathrm{C}$ or vitamin $\mathrm{E}$ in protecting against Hcy-induced apoptosis [19] but capable of reducing intracellular superoxide levels independently from Hcy levels [20], indicating a different anti-oxidative mechanism of folate from that of Hcy.

Recent studies suggest that eHcy is an independent risk factor for cardiovascular diseases and responsible for about 10 percent of total risk [2]. The relationship between plasma Hcy levels and risk of cardiovascular diseases and stroke is as follows: $7 \mu \mathrm{M}$, low; 8-11 $\mu \mathrm{M}$, moderate; $12-16 \mu \mathrm{M}$, high; $16 \mu \mathrm{M}$, very high [21]. An increase of 1 $\mu \mathrm{mol} / \mathrm{l}$ in plasma Hcy corresponds to a 151 gram decrease in birth weight in the third trimester of Japanese women who's intake of folate was only dietary [22]. Additionally, evidence from clinical studies relating eHcy to neurologic disorders appears to be compelling [3-6,8], though the possibility that eHcy may be related to the side effects of medication, such as levodopa, [5,23] and normal physiologic conditions [3] cannot be dismissed. eHcy may have an uninformed impact on neurodegeneration. Laboratory studies showed eHcy potentiates $A_{\beta}$ neurotoxicity in cultured neurons [15]; enhances the susceptibility of dopaminergic neurons to environmental toxic insults such as rotenone, iron, and MPTP (1-methyl-4-phenyl-1,2,3,6-tetrahydropyridine)induced dopaminergic neuronal death in a mouse model of PD [24]; and accelerates motor neuronal death $[25,26]$. Clinical studies have documented that eHcy causes vascular endothelial cells dysfunction leading to hypercoagulation, atherosclerosis and stroke [3], which may, in turn, play a role in the pathogenesis of neurodegenerative disorders [8]. Notably, those neurologic disorders commonly occur in late adult life, which may suggest possible cumulative effects, such as Hcy, from environments with possible genetic predispositions. Importantly, eHcy level is related with various physiologic and pathologic conditions including old age [3], male sex, cigarette smoking [27], chronic renal insufficiency, high blood pressure, elevated cholesterol level, and lack of exercise [28].

Currently there is no cure for neurodegenerative disorders. The best approach in clinical practice is primarily prevention through modification of acquired risk factors. As eHcy may play a role in promoting early onset of various neurologic disorders, exacerbating the symptoms, and accelerating neurodegeneration, eHcy may become a therapeutic target in tertiary management although evidence of Hcy as a definite risk factor for the development of neurodegenerative disorders is still lacking. Nevertheless, information that eHcy may be causally relevant to neurologic disorders could have important clinical implications, because administration of vitamin B-complex with folate to reduce eHcy is inexpensive, potentially effective, and devoid of adverse effects, therefore, having an exceptionally favorable benefit/ risk ratio $[2,29,30]$. However, the efficacy in prevention of neurologic disorders remains to be elucidated and in debate [21]. Well-designed prospective randomized placebo-controlled clinical trials are warranted to evaluate the efficacy of administration of vitamin B-complex with

*Corresponding author: Jin Jun Luo, Departments of Neurology and Pharmacology, Temple University School of Medicine, 3401 North Broad Street, Suite C525, Philadelphia, PA 19140, USA; Tel: 1-215-707-3040; Fax: 1-215-7078235; E-mail: jluo@temple.edu

Received June 17, 2013; Accepted June 20, 2013; Published June 24, 2013

Citation: Luo JJ, Dun NJ (2013) Should Homocysteine be a Therapeutic Target for Neurological Disorders? Brain Disord Ther 2: e107. doi:10.4172/2168975X.1000e107

Copyright: (c) 2013 Luo JJ, et al. This is an open-access article distributed under the terms of the Creative Commons Attribution License, which permits unrestricted use, distribution, and reproduction in any medium, provided the original author and source are credited. 
Citation: Luo JJ, Dun NJ (2013) Should Homocysteine be a Therapeutic Target for Neurological Disorders? Brain Disord Ther 2: e107. doi:10.4172/2168-975X.1000e107

folate to patients with eHcy in preventing the onset, or mitigating the severity, of neurologic disorders.

\section{References}

1. Boushey CJ, Beresford SA, Omenn GS, Motulsky AG (1995) A quantitative assessment of plasma homocysteine as a risk factor for vascular disease. Probable benefits of increasing folic acid intakes. JAMA 274: 1049-1057.

2. Stanger O, Herrmann W, Pietrzik K, Fowler B, Geisel J, et al. (2004) Clinical use and rational management of homocysteine, folic acid, and $B$ vitamins in cardiovascular and thrombotic diseases. Z Kardiol 93: 439-453.

3. Hankey GJ, Eikelboom JW (2001) Homocysteine and stroke. Curr Opin Neurol 14: $95-102$.

4. Hooshmand B, Solomon A, Kåreholt I, Leiviskä J, Rusanen M, et al. (2010) Homocysteine and holotranscobalamin and the risk of Alzheimer disease: a longitudinal study. Neurology 75: 1408-1414

5. Postuma RB, Lang AE (2004) Homocysteine and levodopa: should Parkinson disease patients receive preventative therapy? Neurology 63: 886-891.

6. Zoccolella S, Simone IL, Lamberti P, Samarelli V, Tortelli R, et al. (2008) Elevated plasma homocysteine levels in patients with amyotrophic latera sclerosis. Neurology 70: 222-225.

7. Troen AM (2005) The central nervous system in animal models of hyperhomocysteinemia. Prog Neuropsychopharmacol Biol Psychiatry 29: 1140-1151.

8. Mattson MP, Shea TB (2003) Folate and homocysteine metabolism in neura plasticity and neurodegenerative disorders. Trends Neurosci 26: 137-146.

9. Ho PI, Ortiz D, Rogers E, Shea TB (2002) Multiple aspects of homocysteine neurotoxicity: glutamate excitotoxicity, kinase hyperactivation and DNA damage. J Neurosci Res 70: 694-702.

10. Kruman II, Culmsee C, Chan SL, Kruman Y, Guo Z, et al. (2000) Homocysteine elicits a DNA damage response in neurons that promotes apoptosis and hypersensitivity to excitotoxicity. J Neurosci 20: 6920-6926

11. Mattson MP, Pedersen WA, Duan W, Culmsee C, Camandola S (1999) Cellular and molecular mechanisms underlying perturbed energy metabolism and neuronal degeneration in Alzheimer's and Parkinson's diseases. Ann N Y Acad Sci 893: 154-175.

12. Grünewald T, Beal MF (1999) Bioenergetics in Huntington's disease. Ann N Y Acad Sci 893: 203-213.

13. Lipton SA, Kim WK, Choi YB, Kumar S, D'Emilia DM, et al. (1997) Neurotoxicity associated with dual actions of homocysteine at the N-methyl-D-aspartate receptor. Proc Natl Acad Sci USA 94: 5923-5928.

14. Flott-Rahmel $B$, Schürmann $M$, Schluff $P$, Fingerhut $R$, Musshoff $U$, et al. (1998) Homocysteic and homocysteine sulphinic acid exhibit excitotoxicity in organotypic cultures from rat brain. Eur J Pediatr 2: S112-S117.

15. Ho PI, Collins SC, Dhitavat S, Ortiz D, Ashline D, et al. (2001) Homocysteine potentiates beta-amyloid neurotoxicity: role of oxidative stress. J Neurochem 78: $249-253$
16. Upchurch GR Jr, Welch GN, Fabian AJ, Freedman JE, Johnson JL, et al. (1997) Homocyst(e)ine decreases bioavailable nitric oxide by a mechanism involving glutathione peroxidase. J Biol Chem 272: 17012-17017.

17. Henning SM, Swendseid ME, Ivandic BT, Liao F (1997) Vitamins C, E and A and heme oxygenase in rats fed methyl/folate-deficient diets. Free Radic Biol Med 23: 936-942.

18. Huang HY, Appel LJ, Croft KD, Miller ER 3rd, Mori TA, et al. (2002) Effects of vitamin $\mathrm{C}$ and vitamin $\mathrm{E}$ on in vivo lipid peroxidation: results of a randomized controlled trial. Am J Clin Nutr 76: 549-555.

19. Doshi SN, McDowell IF, Moat SJ, Lang D, Newcombe RG, et al. (2001) Folate improves endothelial function in coronary artery disease: an effect mediated by reduction of intracellular superoxide? Arterioscler Thromb Vasc Biol 21: 11961202.

20. Shea TB, Rogers E (2002) Folate quenches oxidative damage in brains of apolipoprotein E-deficient mice: augmentation by vitamin E. Brain Res Mol Brain Res 108: 1-6.

21. Toole JF, Malinow MR, Chambless LE, Spence JD, Pettigrew LC, et al. (2004) Lowering homocysteine in patients with ischemic stroke to prevent recurrent stroke, myocardial infarction, and death: the Vitamin Intervention for Stroke Prevention (VISP) randomized controlled trial. JAMA 291: 565-575.

22. Takimoto H, Mito N, Umegaki K, Ishiwaki A, Kusama K, et al. (2007) Relationship between dietary folate intakes, maternal plasma total homocysteine and B-vitamins during pregnancy and fetal growth in Japan. Eur J Nutr 46: 300-306.

23. Liu XX, Wilson K, Charlton CG (2000) Effects of L-dopa treatment on methylation in mouse brain: implications for the side effects of L-dopa. Life Sci 66: 2277-2288.

24. Duan W, Ladenheim B, Cutler RG, Kruman II, Cadet JL, et al. (2002) Dietary folate deficiency and elevated homocysteine levels endanger dopaminergic neurons in models of Parkinson's disease. J Neurochem 80: 101-110.

25. Adalbert R, Engelhardt JI, Siklós L (2002) DL-Homocysteic acid application disrupts calcium homeostasis and induces degeneration of spinal motor neurons in vivo. Acta Neuropathol 103: 428-436.

26. Chung $\mathrm{YH}$, Hong JJ, Shin CM, Joo KM, Kim MJ, et al (2003) Immunohistochemical study on the distribution of homocysteine in the central nervous system of transgenic mice expressing a human Cu/Zn SOD mutation. Brain Res 967: 226-234.

27. Haj Mouhamed D, Ezzaher A, Neffati F, Douki W, Najiar MF (2011) Effect of cigarette smoking on plasma homocysteine concentrations. Clin Chem Lab Med 49: 479-483.

28. Nygård O, Vollset SE, Refsum H, Stensvold I, Tverdal A, et al. (1995) Tota plasma homocysteine and cardiovascular risk profile. The Hordaland Homocysteine Study. JAMA 274: 1526-1533.

29. Clarke R, Armitage J (2000) Vitamin supplements and cardiovascular risk: review of the randomized trials of homocysteine-lowering vitamin supplements. Semin Thromb Hemost 26: 341-348.

30. Cockroft DL (1991) Vitamin deficiencies and neural-tube defects: human and animal studies. Hum Reprod 6: 148-157. 